\title{
Histopathological spectrum of Psoriasiform dermatitis
}

\author{
Jayalakshmy $\mathrm{PL}^{1}$, Babitha $\mathrm{AM}^{2}$, Sankar $\mathrm{S}^{1}$, Nandakumar $\mathrm{G}^{3}$ \\ ${ }^{I}$ Department of Pathology, Government Medical College, Kottayam, India \\ ${ }^{2}$ Department of Pathology, MES Medical College, Malappuram, India \\ ${ }^{3}$ Department of Pathology, Government Medical College, Thiruvananthapuram, India
}

\section{Keywords: \\ Psoriasiform; \\ Dermatitis; \\ Inflammatory; \\ Histopathological}

\begin{abstract}
Background: Psoriasiform dermatitis is a frequently encountered terminology in a wide variety of inflammatory dermatoses. It often poses challenges to both dermatologists and pathologists alike. Clinical features when considered alone may not be reliable, as they vary with both disease duration and treatment. On the contrary, histopathological material constitutes definite hard evidence, which can be preserved and will continue to be available for future review. The objective of the study is to study the histopathological findings in Psoriasiform dermatitis.
\end{abstract}

Materials and Methods: This is a retrospective study in a tertiary care centre in Kerala, South India. All cases diagnosed as Psoriasis or mentioned as one of the differential diagnosis were included. The material included 66 skin biopsies. Patients with a previous diagnosis of the same were excluded from the study.

Results: The lesions comprised $9 \%$ of the total number of skin biopsies. The age distribution pattern revealed that the highest percentage was in the 41-60 year age group (50\%) with a male preponderance of $65 \%$. Psoriasis was the most common lesion (60.60\%) and Lichen simplex chronicus was the second most common lesion (10.60\%), encountered in the study.

Conclusion: Some of the histopathological features are specific and characteristic for each entity like Psoriasis, Pityriasis rubra pilaris, Pityriasis rosea and Inflammatory linear verrucous epidermal nevus whereas some overlap in lesions like Prurigo nodularis, Lichen simplex chronicus and Allergic contact dermatitis. Hence, combination of proper clinical observation and histopathological study will give a conclusive diagnosis.

\section{INTRODUCTION}

Psoriasiform dermatitis (PD) encompasses a wide array of inflammatory dermatoses, some of which show both clinical

\author{
Correspondence: \\ Dr. Jayalakshmy Payippat Leelamma, $M D$ \\ Department of Pathology \\ Government Medical College, Kottayam, Kerala, India \\ E-mail: jayafloyyd@gmail.com
}

and histopathological overlap. The term psoriasiform implies that the lesion either clinically or histopathologically mimics psoriasis. This group includes: psoriasis, seborrheic dermatitis, pityriasis rubra pilaris, allergic dermatitis, atopic dermatitis, nummular dermatitis, lichen simplex chronicus, prurigo nodularis, pityriasis rosea, inflammatory linear verrucous epidermal nevus and mycosis fungoides. ${ }^{1,2}$

It is an intimidating task even to experienced pathologists 
Table 1: Distrubution of Psoriasiform dermatitis according to age

\begin{tabular}{lcccccc}
\hline Age group(yrs) & Psoriasis & LSC & PN $\dagger$ & PR $\neq$ & OTHERS & Total \\
\hline$<\mathbf{2 0}$ & $2(5 \%)$ & - & - & - & $2(18 \%)$ & $4(6 \%)$ \\
\hline $\mathbf{2 0 - 4 0}$ & $5(12.5 \%)$ & $2(29 \%)$ & - & $3(100 \%)$ & - & $10(15 \%)$ \\
\hline $\mathbf{4 1 - 6 0}$ & $24(60 \%)$ & $5(71 \%)$ & $4(80 \%)$ & - & $5(45 \%)$ & $38(58 \%)$ \\
\hline$>\mathbf{6 0}$ & $9(22.5 \%)$ & - & $1(20 \%)$ & - & $4(37 \%)$ & $14(21 \%)$ \\
\hline Total & $\mathbf{4 0}(\mathbf{1 0 0} \%)$ & $\mathbf{7 ( 1 0 0 \% )}$ & $\mathbf{5 ( 1 0 0 \% )}$ & $\mathbf{1 8 ( 3 5 . 3 \% )}$ & $\mathbf{1 1}(\mathbf{1 0 0} \%)$ & $\mathbf{6 6}(\mathbf{1 0 0} \%)$ \\
\hline
\end{tabular}

* Lichen simplex chronicus; $†$ Prurigo nodularis; $¥$ Pityriasis rosea

Table 2: Distribution of Psoriasiform dermatitis as per sex

\begin{tabular}{lccc}
\hline \multicolumn{1}{c}{ Disease } & Male (\%) & Female (\%) & Total \\
\hline Psoriasis & $30(75 \%)$ & $10(25 \%)$ & $40(100 \%)$ \\
\hline LSC* & $2(29 \%)$ & $5(71 \%)$ & $7(100 \%)$ \\
\hline Prurigo nodularis & $4(80 \%)$ & $1(20 \%)$ & $5(100 \%)$ \\
\hline Pityriasis rubra pilaris & $2(40 \%)$ & $3(60 \%)$ & $5(100 \%)$ \\
\hline Allergic dermatitis & $0(0 \%)$ & $4(100 \%)$ & $4(100 \%)$ \\
\hline Pityriasis rosea & $3(100 \%)$ & $0(0 \%)$ & $3(100 \%)$ \\
\hline ILVEN $\dagger$ & $2(100 \%)$ & $0(0 \%)$ & $2(100 \%)$ \\
\hline Total & $\mathbf{4 3 ( 6 5 \% )}$ & $\mathbf{2 3 ( 3 5 \% )}$ & $\mathbf{6 6 ( 1 0 0 \% )}$ \\
\hline
\end{tabular}

* Lichen simplex chronicus $; \dagger$ Inflammatory linear epidermal nevus

to give a precise diagnosis every time and one relies heavily on clinical correlation. ${ }^{3}$ However, it is possible to assign specific diagnoses in most cases with a logical and systematic histopathological approach. ${ }^{3}$ A definitive histopathological diagnosis goes a long way in the treatment of such inflammatory dermatoses.

Major reaction patterns in inflammatory skin disease are Lichenoid reaction, Psoriasiform reaction, Spongiotic reaction, Vesiculo-bullous reaction, Granulomatous reaction and Vasculopathic reaction. The present study lays emphasis on histopathological features of Psoriasiform dermatitis.

\section{MATERIALS AND METHODS}

The study was conducted in a tertiary care centre in Kerala, South India, over a period of one year from January 2008 to December 2008. Ethical clearance was obtained from the institutional review committee. All cases of skin biopsy with a clinical diagnosis of Psoriasis or Psoriasis given as one of the differential diagnoses were included in the study. The material included 66 skin biopsies. Patients with a previous diagnosis of the same were excluded from the study. The slides and blocks were retrieved from the archives and multiple serial sections were taken for each biopsy and stained with routine haematoxylin and eosin stain. The important histopathological features observed were subsequently noted on a proforma. The different microscopic features were compared between the cases. Statistical analysis was performed wherever necessary using Excel.

\section{RESULTS}

The present study is a comprehensive analysis of 66 cases of PD which constituted 9\% of the 590 skin biopsies received at the centre over a period of one years. Age distribution of the study group is given in Table 1 . The maximum number of cases of PD, 38 out of $66(58 \%)$, were in the age range of 41-60 years and the least number of cases, 4 out of $66(6 \%)$, were in the youngest age range of $<20$ years. In Table 2 , the sex distribution pattern revealed that most of the cases of PD, 43 out 66 (65\%), were males as compared to females $(35 \%)$.

Distribution of PD as per histopathology is shown in Table 3. The most common diagnosis found on histopathology was Psoriasis. It constituted 40 out of 66 cases $(60.60 \%)$. Histopathological pattern of Psoriasis is given in Table 4. Histological features commonly seen were hyperkeratosis, parakeratosis, even psoriasiform hyperplasia, Munro microabscess, spongiform pustule of Kogoj, suprapapillary thinning of epidermal plates, hypogranulosis, dilated capillaries in papillary dermis and dermal inflammation. (fig. 1-2)

Lichen simplex chronicus (LSC) constituted the second most common diagnosis with 7 out of 66 cases $(10.60 \%)$. The most common features observed were hyperkeratosis, diffuse parakeratosis, uneven psoriasiform hyperplasia with supra papillary thickening and perivascular lymphocytic infiltrate in dermis. (fig.3) Five cases (7.57\%) belonged to the category of Prurigo nodularis (PN). The features noted 
Table 3: Distribution of cases in Psoriasiform dermatitis

\begin{tabular}{clc}
\hline S.N. & $\begin{array}{l}\text { Histopathological } \\
\text { diagnosis }\end{array}$ & $\begin{array}{c}\text { Number of cases } \\
(\%)\end{array}$ \\
\hline 1 & Psoriasis & $40(60.60 \%)$ \\
\hline 2 & Lichen simplex chronicus & $7(10.60 \%)$ \\
\hline 3 & Prurigo nodularis & $5(7.57 \%)$ \\
\hline 4 & Pityriasis rubra pilaris & $5(7.57 \%)$ \\
\hline 5 & $\begin{array}{l}\text { Allergic contact } \\
\text { dermatitis }\end{array}$ & $4(6.06 \%)$ \\
\hline 6 & Pityriasis rosea & $3(4.54 \%)$ \\
\hline 7 & ILVEN * & $2(3.03 \%)$ \\
\hline & Total & $\mathbf{6 6}(\mathbf{1 0 0} \%)$ \\
\hline
\end{tabular}

*Inflammatory linear epidermal nevus

were compact orthokeratosis with parakeratosis, uneven psoriasiform hyperplasia and focal hypergranulosis. (fig.4)

Five cases (7.57\%) belonged to the category of Pityriasis rubra pilaris (PRP). Follicular plugging, focally thin granular layer, parakeratosis alternating with orthokeratosis, uneven psoriasiform hyperplasia with short and broad rete ridges and perivascular lymphocytic infiltrate were the common features noted. (fig.5) One case showed perifollicular infiltrate of lymphocytes. Four cases $(6.06 \%)$ showed features of Allergic contact dermatitis with uneven psoriasiform hyperplasia, mild spongiosis, thick suprapapillary plate and perivascular lymphocytic infiltrate in dermis. (fig.6)

Three cases (4.54\%) showed features of Pityriasis rosea (PR) with hyperkeratosis, absent granular cell layer, uneven psoriasiform hyperplasia, extravasated erythrocytes in upper dermis and homogenous papillary collagen. (fig.7) Two cases $(3.03 \%)$ showed features of Inflammatory linear verrucous epidermal nevus (ILVEN) with alternating depressed foci of orthokeratosis with preserved granular layer, elevated foci of parakeratosis with absent granular layer, uneven psoriasiform hyperplasia with elongated rete ridges and papillomatosis. (fig.8). Dermis showed perivascular mononuclear inflammatory infiltrate.

\section{DISCUSSION}

Histologically, psoriasiform reaction pattern is defined as the presence of epidermal hyperplasia with elongation of rete ridges in a regular manner. The presence of evenly elongated, thin rete ridges with equally long dermal papillae can imply only one condition, i.e., psoriasis. ${ }^{3}$ All other diseases exhibit an uneven psoriasiform pattern, i.e., rete ridges are of uneven lengths and thickness with thick suprapapillary plates. ${ }^{3}$ According to Ackerman et al, psoriasiform pattern forms a major subset of perivascular dermatitis, the largest group of inflammatory skin diseases. ${ }^{4}$

Psoriasis, the prototype of PD, is a genetically determined, inflammatory and proliferative disease of the skin characterized by dull red, sharply demarcated scaly plaques. ${ }^{5}$ The two clinical signs, Auspitz's sign and the Grattage test have been described as pathognomonic of psoriasis by Hellgren et al. ${ }^{6}$ Regular epidermal hyperplasia, dilated blood vessels in papillary dermis and presence of Munro microabscess and/or Kogoj's abscess have been described to be the most constant or characteristic histopathological features in skin biopsy of psoriasis. ${ }^{7}$ Similarly, spongiosis, irregular epidermal hyperplasia and absence of Munro micro and Kogoj's abscess have been found consistently in psoriasiform dermatitis. ${ }^{7}$

Table 4: Histopathological pattern of Psoriasis

\begin{tabular}{lc}
\hline Histology & Number of cases (\%) \\
\hline Acanthosis (regular) & $40(100)$ \\
\hline Parakeratosis & $40(100)$ \\
\hline Suprapapillary thinning & $40(100)$ \\
\hline Lymphocytes in dermis & $40(100)$ \\
\hline Hypogranulosis & $39(97.5)$ \\
\hline Dilated capillaries in dermis & $38(95)$ \\
\hline Elongated rete ridges & $36(90)$ \\
\hline Munro microabscess & $35(87.5)$ \\
\hline Hyperkeratosis & $10(25)$ \\
\hline Kogoj pustules & $5(12.5)$ \\
\hline
\end{tabular}

Table 5: Comparison of Histoogical features of Psoriasis

\begin{tabular}{|c|c|c|c|c|}
\hline Histology & Lal $(n=25) \%$ & Gordon $(n=100) \%$ & Mehta $(n=58) \%$ & $*(n=40) \%$ \\
\hline Acanthosis & 100 & 100 & 93.10 & 100 \\
\hline Hyperkeratosis & - & 28 & - & 25 \\
\hline Parakeratosis & 92 & 97 & 65.5 & 100 \\
\hline Munro microabscess & 20 & 75 & - & 87.5 \\
\hline Suprapapillary thinning & 88 & 98 & 65.51 & 100 \\
\hline Hypogranulosis & 72 & 75 & 87.93 & 97.5 \\
\hline Kogoj pustules & - & 31 & - & 12.5 \\
\hline Dilated capillaries & - & 96 & 91.37 & 95 \\
\hline Lymphocytic infiltration & 100 & 95 & - & 100 \\
\hline
\end{tabular}

*Present study 


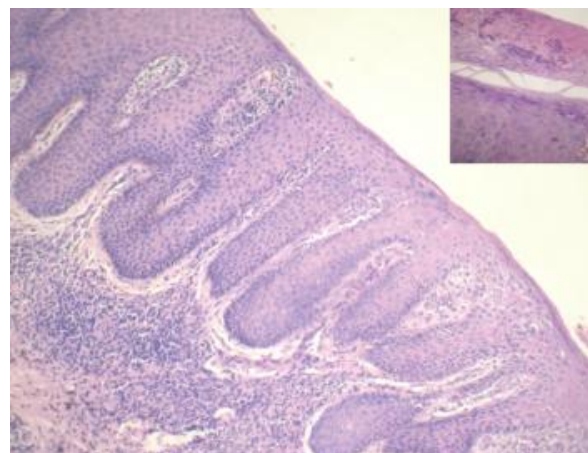

Figure 1: Psoriasis showing regular acanthosis,elongated rete ridges, suprapapillary thinning, Munro microabscess (inset), hypogranulosis and lymphocytic infiltration in papillary dermis (HE Stain, X10).

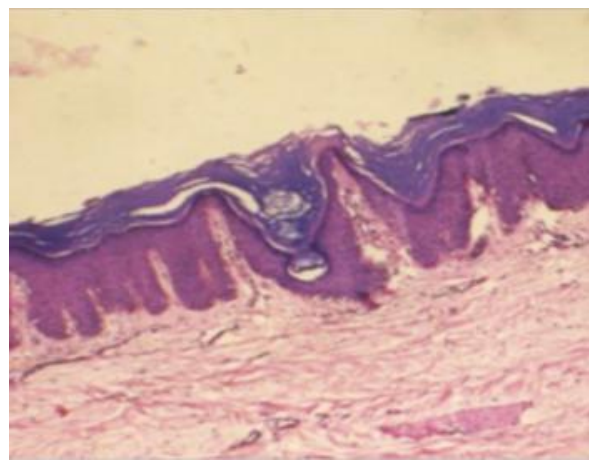

Figure 3: Lichen simplex chronicus showing hyperkeratosis, diffuse parakeratosis, uneven psoriasiform hyperplasia with supra papillary thickening and perivascular lymphocytic infiltrate in dermis (HE Stain, X100).

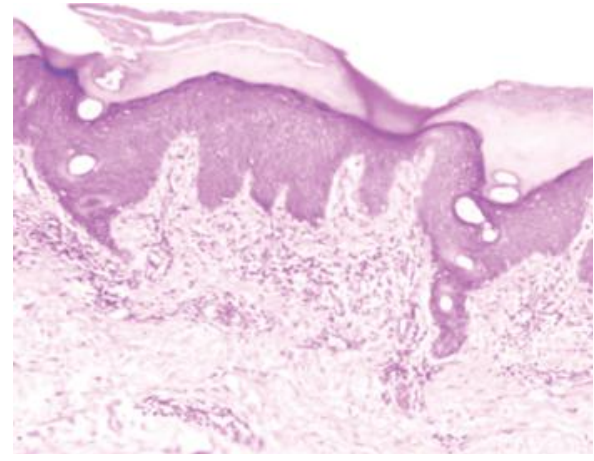

Figure 5: $P R P$ showing follicular plugging,parakeratosis alternating with orthokeratosis, uneven psoriasiform hyperplasia with short and broad rete ridges and perivascular lymphocytic infiltrate were (HE Stain, X100).

In the present study, there were 40 cases of Psoriasis and it was seen commonly above 40 yrs of age, 24 out of 40 cases $(60 \%)$; this was in accordance with Alexander et $\mathrm{al}^{8}$, who reported psoriasis being common in age group of 41-50 yrs. Thirty out of 40 cases $(75 \%)$ were males and $10(25 \%)$ were females with male to female ratio of $3: 1$. Kaur et al ${ }^{9}$,

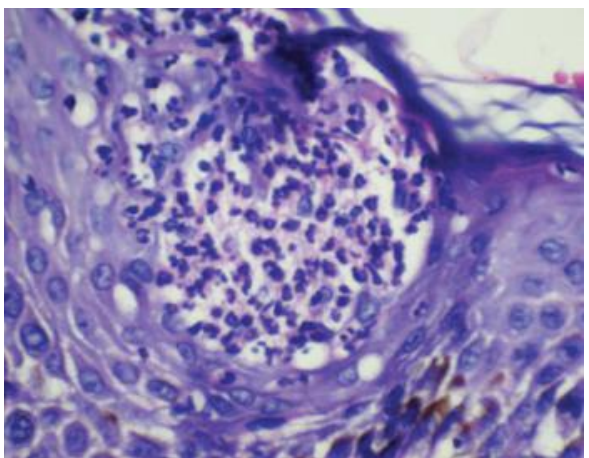

Figure 2: Psoriasis showing spongiotic pustule of Kogoj (HE Stain, X40).

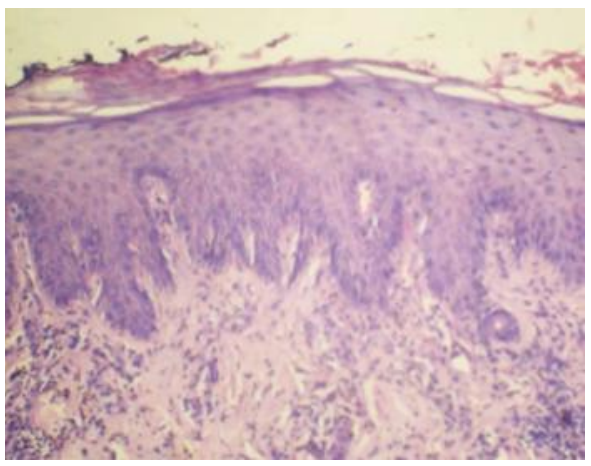

Figure 4: Prurigo nodularis showing compact orthokeratosis with parakeratosis, uneven psoriasiform hyperplasia (HE Stain, X100).

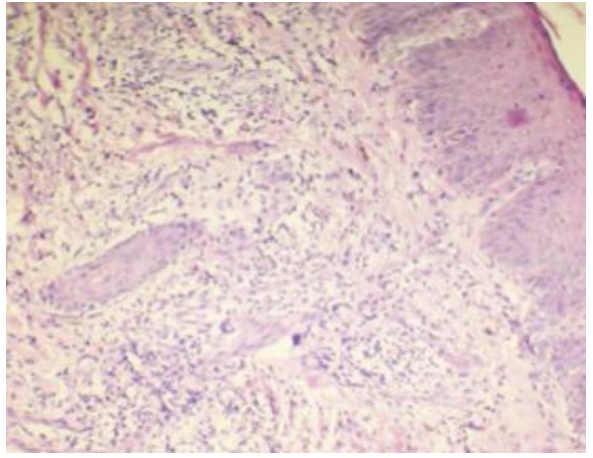

Figure 6: Allergic contact dermatitis showing uneven psoriasiform hyperplasia,thick suprapapillary plate and perivascular lymphocytic infiltrate in dermis (HE stain, X100).

Alexander et $\mathrm{al}^{8}$ and Yang et $\mathrm{al}^{10}$ also noted high prevalence in males.

Comparison of histopathological features of psoriasis is given in Table 5. Various histopathological studies of psoriasis like Lal et al ${ }^{11}$, Gordon and Johnson ${ }^{12}$ and Mehta 


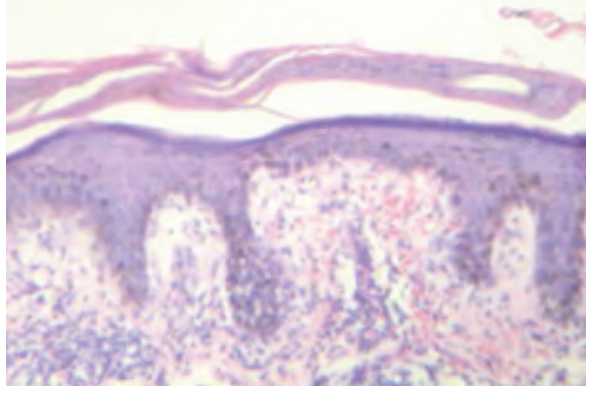

Figure 7: PR showing hyperkeratosis, absent granular cell layer, uneven psoriasiform hyperplasia and extravasated erythrocytes in upper dermis (HE Stain,X100).

et al ${ }^{13}$ also noted parakeratosis, acanthosis, suprapapillary thinning, Munro microabscesses and hypogranulosis in most of the cases. The present study also noted similar histological findings in majority of the cases of psoriasis. Mehta et $\mathrm{al}^{13}$ stated that, suprapapillary thinning and the absence of granular cell layer could be added to the list of essential histopathological criteria for psoriasis, in addition to Munro microabscess and Kogoj's abscess.

Seven out of 66 cases $(60.60 \%)$ were that of LSC. Most of the cases, 5 out of 7 (71\%), were reported in 41-60 year age group. 5 out of 7 cases $(71 \%)$ were females. According to Lotti et $\mathrm{al}^{14}$, LSC is observed more commonly in females compared to males, adults than in children and the microscopic features include stratified squamous epithelium exhibiting orthokeratosis, parakeratosis, acanthosis, and irregular hyperplasia of the rete pegs. The present study also noted similar nonspecific histological findings.

Five cases $(7.57 \%)$ of PN were observed out of which 4 cases $(80 \%)$ were in the $40-60$ year age group and one case $(20 \%)$ was in the 41-60 year age group. According to Darshan et $\mathrm{al}^{15}$, PN most commonly affects the middleaged and elderly, although it has been seen in young men and children as well. There is no sex predilection but our study had a male preponderance (4 males, 1 female). PN shares some features with both psoriasis and ichthyosis as it demonstrates parakeratotoic hyperkeratosis accompanied by acanthosis and papillomatosis. ${ }^{15}$ The cases in our study also had histological overlap with psoriasis because of hyperkeratosis, parakeratosis and acanthosis.

PRP was diagnosed in 5 patients ( 2 males, 3 females). Age of onset ranged between 20 and 40 years. Age group, sex and histological features of PRP in our study were comparable to those conducted by Marrouche $\mathrm{N}$ et al. ${ }^{16}$ Microscopically, follicular plugging in addition to checkerboard alternating orthokeratosis/parakeratosis may serve as clues to PRP diagnosis.

Allergic contact dermatitis was diagnosed in 4 patients (4

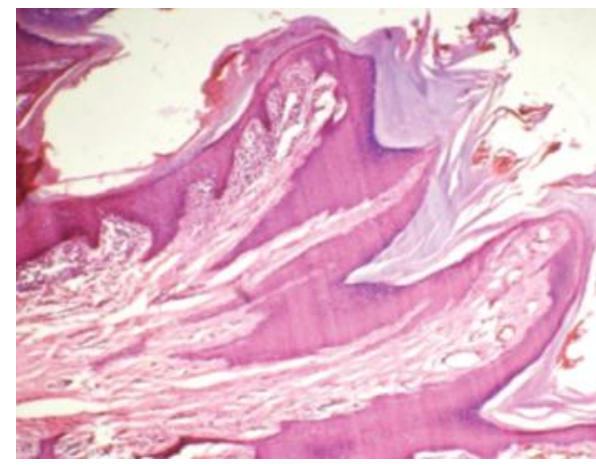

Figure 8: ILVEN showing uneven psoriasiform hyperplasia,depressed foci of orthokeratosis with preserved granular layer and elevated foci of parakeratosis with absent granular layer (HE Stain,X40).

females). There was no age predilection. D.L Jovanovi et a ${ }^{17}$ states that the value of light microscopic examination in order to differentiate between allergic contact dermatitis and chronic dermatitis is limited and it must be considered together with results of clinical examination and other tests. All four cases in our study had non-specific microscopic features like hyperkeratosis, acanthosis and chronic inflammatory infiltrate in dermis.

Prasad D et a $1^{18}$ had 3 cases of PR and 2 out of 3 cases were females. All were in 31-40 year age group. In the present study, there were 3 cases of PR and they were observed in 20-40 year age group but all 3 cases were females. Some of the features of PR observed by Prasad D et al were comparable with our study namely absence of granular cell layer, extravasation of red blood cells in papillary dermis and homogenization of papillary collagen.

ILVEN is a distinct variety of keratinocytic epidermal naevus that appears at birth or early childhood, is 4 times more common in girls and has a linear distribution following the Blaschko lines. ${ }^{19}$ But in the present study, it was seen in 2 males and both were below 5 years of age.

Histopathologic findings in our study were more or less similar to a study by Bandyopadhyay et $\mathrm{al}^{20}$ with psoriasiform hyperplasia of the epidermis, varying amount of spongiosis, parakeratosis with hypogranulosis alternating with orthokeratosis with hypergranulosis and variable upper dermal perivascular lymphocytic infiltrate.

\section{CONCLUSION}

Psoriasis has varied clinical presentations and there is overlap of both clinical patterns and distribution of PD, which often makes clinical diagnosis difficult. Some of the histopathological features are specific and characteristic for each entity like Psoriasis, Pityriasis rubra pilaris, Pityriasis rosea and Inflammatory linear verrucous epidermal nevus whereas some overlap in lesions like Prurigo nodularis, Lichen simplex chronicus and Allergic contact dermatitis. 
Hence, combination of proper clinical observation and histopathological study will give a conclusive diagnosis.

\section{ACKNOWLEDGMENT}

I would like to acknowledge Dr. Deepa S, Assistant Professor for providing guidance and Dr. Binu Jose, Senior Resident for the assistance given in collecting data.

\section{REFERENCES}

1. Altman E, Kamino H. Diagnosis: Psoriasis or not? What are the clues? Semin Cutan Med Surg 1999;18:25-35. Crossref

2. Barr RJ, Young EM Jr. Psoriasiform and related papulosquamous disorders. J Cutan Pathol 1985;12:412-25. Crossref

3. Tirumalae R. Psoriasiform Dermatoses: Microscopic Approach. Indian J Dermatol $2013 ; 58: 290-3$. Crossref

4. Ackerman B, Chongchitnant N, Sanchez J. Inflammatory disease. In: Ackerman B, Chongchitnant N, Sanchez J, Guo Y, Bennin B, Reichel M, et al., editors. Histologic diagnosis of inflammatory skin conditions: An algorithmic method based on pattern analysis. 2nd ed. Philadelphia: Williams and Wilkins; 1997. p. 663-73.

5. Camp RD. Psoriasis. In: Champion RH, Burton JL, Burns DA, Breathnach SM, editors. Rooks textbook of dermatology. 6th ed. Oxford: Blackwell Publication; 1998. p. 1589-651.

6. Hellgren L. The prevelance in sex, age and occupational groups in total population in Sweden. In: Hellgren L, editor.Psoriasis. 1st ed. Stockholm: Almqvist and Wiksell; 1967. p. 134-45.

7. Toussaint S, Hideko K. Non infectious erythematous popular and squamous diseases of the skin. In: Elder D, Elenitsas R, Jaworsky C, Johnson B, editors. Lever's Histopathology of the skin. 8th ed. Philadelphia: Lippincott-Raven publishers; 1997. p. 156-63.

8. Alexander E, Pinto J, Pai GS, Kamath N, Kuruvilla M. Disease concomitance in psoriasis: a clinical study of 61 cases. Indian J Dermatol Venerol Leprol 2001;67:66-8. Crossref

9. Kaur I, Kumar B, Sharma VK, Kaur S. Epidemiology of psoriasis in a clinic from North India. Indian J Dermatol Venerol Leprol 1986;52:208-12.
10. Yang Y, Koh D, Khoo L, Nyunt SZ, Ng V, Goh CL. The pso $\neg$ riasis disability index in Chinese patients: Contribution of clinical and psychological variables. Int J Dermatol 2005;44:925-9. Crossref

11. Lal S, Sadana SR, Chitkara NL. Histopathology of Psoriasis at Various Stages. Indian J Dermatol Venereol Leprol 1965;31:216-22.

12. Gordon M, Johnson WC. Histopathology and histochemistry of psoriasis. The active lesion and clinically normal skin. Arch Dermatol 1967;95:402-7. Crossref

13. Mehta S, Singal A, Singh N, Bhattacharya SN. A study of clinicohistopathological correlation in patients of psoriasis and psoriasiform dermatitis. Indian J Dermatol Venereol Leprol 2009;75:100. Crossref

14. Lotti T, Buggiani G, Prignano F. Prurigo nodularis and lichen simplex chronicus. Dermatol Ther 2008;21:42-6. Crossref

15. Darshan C Vaidya, Robert A Schwartz. Prurigo Nodularis: A Benign Dermatosis Derived from a Persistent Pruritus. Acta Dermatovenerol Croat 2008;16:38-44.

16. Marrouche N, Kurban M, Kibbi AG, Abbas O.Pityriasis rubra pilaris: clinicopathological study of 32 cases from Lebanon. Int J Dermatol 2014;53:434-9. Crossref

17. Jovanovi DL, Petrovi A, Paravina M, Stanojevi M and Bini I. Chronic contact allergic and irritant dermatitis of palms and soles: routine histopathology not suitable for differentiation. Acta Dermatoven APA 2003;12:127-130.

18. Prasad D, Mittal R R, Walia R, Popli R. Pityriasis rosea: A histopathologic study. Indian J Dermatol Venereol Leprol 2000;66:244-6. Crossref

19. Altman J, Mehregan AH. Inflammatory linear verrucous epidermal nevus. Arch Dermatol 1971; 104: 385-9. Crossref

20. Bandyopadhyay D, Saha A. Genital/perigenital inflammatory linear verrucous epidermal nevus: A case series. Indian J Dermatol 2015;60:592-5. Crossref 